\title{
Science, realism, and unconceived alternatives: introduction to the special issue on unconceived alternatives
}

\author{
Sindhuja Bhakthavatsalam ${ }^{1} \cdot$ Ian James Kidd ${ }^{1}$
}

Published online: 10 September 2019

(c) Springer Nature B.V. 2019

The problem of unconceived alternatives was introduced by Kyle Stanford in his 2006 book, Exceeding our Grasp. Its main thesis was that there is good historical evidence that scientific communities have, historically, consistently failed to conceive of plausible alternatives in fundamental domains of science. Moreover, this failure to exhaust the space of epistemic possibilities could still be a deep feature of our epistemic situation, in ways that seriously challenge realist claims about science. An energetic literature has emerged that develops and challenges Stanford's articulation of the problem, his use of historical evidence, and the anti-realist conclusions which he draws. To capitalise on those debates, we organised a two-day workshop at the University of Durham to take stock of the debate. This collection is the fruit of that event.

Stanford's original statement of the problem of unconceived alternatives, as offered in Exceeding our Grasp, mainly relied on historical case studies to demonstrate its motivating claim that the historical record gives us good reason to think that scientific communities have consistently failed to conceive of plausible alternatives to fundamental theories they did in fact develop. Many scientific realists responded that, even if that were true, this is an historical feature of scientific communities, rather than their more sophisticated successors. If so, the problem is confined to the past, and should not disturb our confidence in present and future scientific communities. In his contribution to this Special Issue, Stanford argues the contrary: there are several entrenched features of the structure and organisation of contemporary scientific communities that actually reduces their capacity to generate revolutionary, transformative, or unorthodox theories. If that's right, then contemporary scientific communities are actually more vulnerable to the problem of unconceived alternatives, due to the entrenched epistemic conservatism now baked into their structures.

An interest in the social-epistemic dimensions of science connects to an interest in the implications of the problem of unconceived alternatives for science construed

\footnotetext{
$凶 \quad$ Ian James Kidd

Ian.Kidd@nottingham.ac.uk

1 Nottingham, UK
} 
as a large-scale, multigenerational enterprise. Samuel Ruhmkorff has argued in earlier work that we do not have historical evidence for the existence of unconceived alternatives. In this paper, he argues that we may come to have such evidence into the future, and that this possibility has epistemic consequences for our responses to the force of the problem of unconceived alternatives for scientific realism. Crucially, adoption of certain forms of instrumentalism can be epistemically injurious for scientific practice, especially since-as Rowbottom argues, in his contribution to this Special Issue-one could expand quite considerably the scope of the unconceived. Rumhkorff connects this to the reality of scientific enquiry as a 'multigenerational collective process', dramatized as what he calls the cathedral problem: 'what should we believe about our best scientific theories if their validation against the possibility of plausible unconceived alternatives - if any such validation is in the offing - will come long after we are gone?' On this view, our thinking about the epistemological significance of unconceived alternatives ought to be historical in a double sense-informed by the past science, concerned for future science.

The scope of the unconceived is the theme of the contribution by Darrell P. Rowbottom. The debate about unconceived alternatives, as introduced by Stanford, focused onto fundamental theories about the nature of reality. Interestingly, though, the sorts of social and historical processes that led to the putative failures to conceive of theories could also have led to similarly failures to conceive of other epistemic objects, too. Rowbottom takes up this possibility by expanding the scope of the failures to conceive to include, inter alia, observations, models, predictions, explanations, methods, instruments, experiments, and values. Simply put, fundamental theories are not the only things that the scientific community, historically and today, has shown itself bad at failing to conceive of alternatives too. Moreover, these other unconceived things are not just more fuel to the fire; the patterns of occlusion they represent interact with one another, which Rowbottom uses to amplify the instrumentalist implications of Stanford's original argument.

The difficult question about our practical and philosophical responses to the possibility of unconceived alternatives is the topic of Jesús Zamora Bonilla's paper in this Special Issue. He opens by arguing that the choice between realist and instrumentalist interpretations of science arise from within scientific practice, and then uses that to ask how that affects our thinking about the problem of 'unconceived alternatives'. If a practicing scientist supposes that there are, or may be, some unconceived alternatives to the theory they currently employ, how, if at all, should that effect their practice? Bonilla develops an epistemic utility function approach to this question, which predicts that scientists will tend to be more instrumentalist-by accepting theories that they regard as likely far from the truth-if they judge that doing so promises empirical payoffs. Taking the prospect of unconceived alternatives seriously, then, can be a matter of pragmatically-driven calculation about their likely benefits for enquiry relative to the costs doing so would incur.

Juha Saatsi argues that some prominent arguments against scientific realism are guilty of systematically overshooting, an unfortunate tendency ultimately generated by certain undue presuppositions about realism. This distorts the dialectic of debates about the role of historical evidence in relation to realism and antirealism, especially encouraging what Saatsi sees as an invidious tendency to draw 'conclusions of an 
unambiguously anti-realist flavour from arguments that actually only demonstrate a tension between the history of science and realism-construed-in-a-certain-way.' If that is the case, then there are construals of realism that can avoid those challenges-ones that avoid the old induction and what Stanford calls his 'new induction'. In the case of Stanford, what is challenged is his specific characterisation of realism as the claim that our best scientific theories about the nature of the world are probably and/or approximately true - a characterisation too optimistic to class as modest in Saatsi's sense.

We-the guest editors - are grateful to the British Society for the Philosophy of Science and the Addison Wheeler Fellowship scheme at the University of Durham for funding this event on which his collection is based and to the audience for their discussion. We're also grateful to the contributors for their patience, and the Editors of the journal.

Publisher's Note Springer Nature remains neutral with regard to jurisdictional claims in published maps and institutional affiliations. 